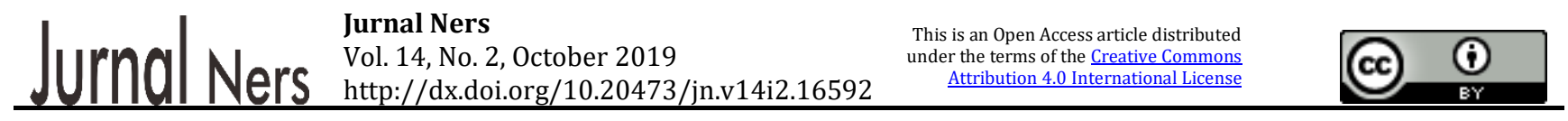

Original Research

\title{
Analysis of the Sociodemographic and Psychological Factors of the Family Caregivers' Self-Management Capabilities for Type 2 Diabetes Mellitus
}

\section{Rondhianto Rondhianto ${ }^{1,2}$, Nursalam Nursalam ${ }^{3}$, Kusnanto Kusnanto ${ }^{3}$, Soenarnatalina Melaniani $^{1}$, Ahsan Ahsan ${ }^{4}$}

${ }^{1}$ Faculty of Public Health, Universitas Airlangga, Surabaya, Indonesia

${ }^{2}$ Faculty of Nursing, Universitas Jember, Jember Indonesia

${ }^{3}$ Faculty of Nursing, Universitas Airlangga, Surabaya, Indonesia

${ }^{4}$ Faculty of Medicine, Universitas Brawijaya, Malang, Indonesia

\begin{abstract}
Introduction: The successful management of Type 2 diabetes mellitus is determined by the role of the family in self-management as a family caregiver. Many factors influence the capability of the family caregivers to carry out diabetes self-management. The purpose of this study was to analyze the factors that influence the family caregiver capability of performing diabetes self-management in people with Type 2 diabetes mellitus.
\end{abstract}

Methods: The study design was an analytical observation using a cross-sectional approach. The sample was 220 family caregivers of people with Type 2 diabetes mellitus in Jember Regency, East Java Province, Indonesia. The multistage random sampling technique was used as the sampling technique. The research instrument was a questionnaire. The questionnaires used in this study were the Diabetes Management Self Efficacy Scale, the Spoken Knowledge in Low Literacy Patients with Diabetes Questionnaire, the Motives for Caregiving Scale, the Spirituality Index of Well-Being, the Sense of Coherence Scale, the Coping Scale, the Hensarling Diabetes Family Support Scale, and the Family Caregiver's Perception of the Role of the Nurse Questionnaire. The data analysis was performed using the Pearson correlation test, the Spearman rank test, and the multiple linear regression test.

Results: The results of the Pearson correlation test and Spearman rank test showed that the sociodemographic factors associated with diabetes self management were age $(p=0.000)$, gender $(p=0.016)$, education $(p=0.000)$, income $(p=0.000)$, and kinship $(p=0.000)$. The psychosocial factors associated with diabetes self management were diabetes knowledge $(\mathrm{p}=0.000)$, motivation $(\mathrm{p}=0.000)$, coping skills $(\mathrm{p}=0.000)$, spirituality $(p=0.000)$, family coherence $(p=0.000)$, family support $(p=0.000)$ and the role of the nurses $(p=0.000)$. The multiple linear regression test showed that the factors associated with diabetes self management were diabetes knowledge $(\beta=0.047)$, motivation $(\beta=0.094)$, coping $(\beta=0.188)$, spirituality $(\beta=-0.082)$, family coherence $(\beta=$ $-0.043)$, family support $(\beta=0.296)$ and the role of the nurses $(\beta=0.512)$.

Conclusion: Efforts to increase the family caregiver's capabilities in terms of diabetes self-management should pay attention to the socio-demographic and psychosocial factors to prevent complications and to improve the health status, and quality of life of people with Type 2 diabetes mellitus.

\section{ARTICLE HISTORY}

Received: Dec 19, 2019

Accepted: Jan 14, 2020

\section{KEYWORDS}

diabetes self management; family caregiver capabilities; psychosocial; sociodemographic factors; type 2 diabetes mellitus

\section{CONTACT}

Rondhianto Rondhianto $\triangle$ rondhianto2017@fkm.unair.ac.id $\Xi^{\prime}$ Faculty of Public Health, Universitas Airlangga, Surabaya, Indonesia

Cite this as: Rondhianto, R., Nursalam, N., Kusnanto, K., Melaniani, S., Ahsan, A. (2019). Analysis of the Sociodemographic and Psychological Factors of the Family Caregivers' Self-Management Capabilities for Type 2 Diabetes Mellitus. Jurnal Ners, 14(2), 215-223. doi:http://dx.doi.org/10.20473/in.v14i2.16592

\section{INTRODUCTION}

Type 2 diabetes mellitus is a chronic disease that cannot be cured. It requires proper medical management, ongoing self-management, and collaboration between the diabetic individual, their family and any associated health workers. This is because the family plays an essential role in the 
successful management of Type 2 diabetes mellitus (World Health Organization [WHO], 2016). The successful management of Type 2 diabetes mellitus is determined by the role of the family in selfmanagement as a family caregiver can help the person with diabetes to manage the disease (Pierce \& Lutz, 2012). This is by helping them to carry out a series of diabetes self-management actions (Powers et al., 2015). However, not all families can play a role as a family caregiver. As a result, this can lead to failure in diabetes self-management (World Health Organization [WHO], 2016). The majority of families $(53.33 \%)$ were unable to carry out their role as family caregivers related to caring for the Type 2 diabetes mellitus patients (Putri, Yeni, \& Handayani, 2013). Other studies showed that the family caregivers who care for people with diabetes have health problems themselves or physical and psychological disorders. This has the impact of them having a decreased ability to carry out the health task of caring for people with diabetes (Badriah, Wiarsih, \& Permatasari, 2017). Furthermore, the failure of a family caregiver in terms of diabetes self management has an impact on their health status. It also increases the complications of people with diabetes (International Diabetes Federation [IDF], 2017). The problem also can increase the care needed in the health care institutions which has an impact in terms of increasing the health cost (World Health Organization [WHO], 2016), decreasing quality of life, reducing life expectancy and increasing the mortality rate (International Diabetes Federation [IDF], 2017).

Diabetes is an incurable disease. It requires continuous care in the long term that can deplete the family's economic resources and disrupt the roles, functions, and regulations in the family. Diabetes also has a negative impact on the other family members in the form of physical and psychological disorders, social disruption and disturbances in the economic stability of the family. These all impact on their capability to carrying out caring actions related to the disease (Pierce \& Lutz, 2012). Families can participate in diabetes self-management to prevent the negative effects of the disease (World Health Organization [WHO], 2018). They can also provide emotional support to the people with diabetes, help them to develop healthy behaviors and promote diabetes self management. This can improve their blood sugar control, reduce the complications of the disease and improve the quality of life of diabetics $(\mathrm{Hu}$ et al., 2014; Matrook et al., 2018). Therefore, it is essential for the health care provider to understand the critical role of the family in managing the disease and to seek to improve the family's capability of managing the disease independently.

Several studies have shown that many factors can affect the capability of the family caregivers in terms of self-management. Sociodemographic factors including age, sex, marital status, socioeconomic status, ethnicity, and kinship can influence how a person conducts independent management of the disease (Friedman, Bowden,\& Jones, 2010; Pierce \&
Lutz, 2012). In addition, several studies show that a person's psychosocial condition such as their knowledge, motivation, coping, family coherence, and aspects of religiosity can also affect how a person should behave in relation to managing the disease of their family members (Antonovsky \& Sourani, 1988; Friedman, Bowden \& Jones, 2010; Pierce \& Lutz, 2012; Rabinowitz et al., 2009; Sakanashi \& Fujita, 2017).

The family caregiver perception factors related to the resources that can be used in efforts to care and support the health services will also determine the ability of the family caregiver to carry out the caregiving role (Friedman, Bowden, \& Jones, 2010; Grant \& Ferrell, 2012; Pierce \& Lutz, 2012). Understanding the interaction between the sociodemographic factors and psychosocial factors with the ability of the family caregivers to manage Type 2 diabetes mellitus can provide insights to improve diabetes management comprehensively. This step was taken to be able to provide positive results in the management of diabetes, namely increased glycemic control and reduced disease complications, and to improve the quality of life of people with Type 2 diabetes mellitus.

\section{MATERIALS AND METHODS}

The study design was an analytical observation with a cross-sectional approach conducted from October 28th until November 28th 2019 in 10 Public Health Centers in Jember Regency, East Java Province, Indonesia. The sample size was 220 family caregivers of Type 2 diabetic patients. This study used multistage random sampling with the following inclusion criteria: (1) spouse or adult children who have a parent with Type 2 diabetes mellitus, (2) living together with people with Type 2 diabetes mellitus, (3) the families of people with Type 2 diabetes mellitus who have been diagnosed with Type 2 diabetes mellitus within a minimum of 1 year and (4) the family has health insurance.

The variables in this study are the family caregiver's diabetes self-management capabilities as the dependent variable and the sociodemographic and psychosocial factors as the independent variables. The sociodemographic factors included age, gender, education level, income level, marital status, kinship with diabetes, diabetes duration and the complications of diabetes. The psychosocial factors included diabetes knowledge, motivation, coping skills, spirituality, family coherence, family support, and the perception of the role of the nurses. The instruments used in this study were questionnaires. All of the questionnaires were tested for validity and reliability, and all of the research variable question items have been declared to be valid and reliable.

The family caregiver diabetes self-management capabilities were measured by the Diabetes Management Self Efficacy Scale by van der Bijl et al. 
(2001). This questionnaire consists of 20 items with a Likert scale of 1-5 which contains beliefs about the ability to regulate Type 2 DM type 2 diets, the regulation of physical activity of patients with Type 2 DM, the use of medication, blood sugar monitoring, and foot care. The sociodemographic factors were measured using questionnaires consisting of questions focused on age, gender, education level, income level, marital status, kinship with diabetics, and also diabetes duration and the complications experienced by people with diabetes.

The Spoken Knowledge in Low Literacy Patients with Diabetes Questionnaire by Rothman et al. (2005) was used to measure the diabetes knowledge variables. This questionnaire contains questions on the knowledge of the signs, symptoms, and management of diabetes. This questionnaire consisted of 20 question items; a correct answer was given a score of 1 while a wrong answer was given a score of 0 . The range of scores was 0-20. The Motives for Caregiving Scale by Kolmer et a. (2008) was used to measure the motivation of the family caregiver when caring for patients with diabetes. This questionnaire contains the aspects of responsibilities and obligations, feeling happy, being the right person and hope. This questionnaire consists of 12 question items with a score of yes (1) and no (0). The score range was $0-12$.

The Spirituality Index of Well Being by Daaleman \& Frey (2004) was used to measure the aspects of family caregiver spirituality, which consists of their self-confidence in life and life schemes. This questionnaire consisted of 12 items with a Likert scale of 1-5. The score range is $12-60$. The Sense of Coherence Scale by Holmefur et al. (2014) was used to measure the family caregiver perception of family coherence. The questionnaire consisted of 13 items with a Likert scale of 1-7 so the score range was 1391. The Coping Scale by Hamby, Grych, \& Banyard (2015) was used to measure the family caregiver coping skills that contained an assessment of their abilities to overcome problems. The questionnaire consisted of 13 items with a Likert scale of 1-4 so the value range was 13-52.

The Hensarling Diabetes Family Support Scale by Hensarling (2009) was used to measure the family caregiver perceptions of family support received in the form of information, an assessment and emotional and instrumental support. The questionnaire consisted of 29 items on a scale of $1-4$, so the score range was $29-116$. The perception of the family care groups of the health services was measured using a questionnaire compiled based on the concept of the role of the nurses of empowering the family (Imanigoghary et al., 2017). This questionnaire consisted of 25 question items that measured the family perceptions on the role of nurses in helping people with diabetes and their families, in the form of enabling ( 9 items), reinforcing (8 items), and supporting ( 7 items) with a Likert scale of $1-4$, so the range of scores was 24-96.
The data collection in the study was carried out with the help of research assistants. Before the data collection, the researcher got informed consent for the study from each respondent. The researcher explained the purpose and benefits of the research, the procedure of conducting the research, and the risk of participating in the research. After it was explained, the researcher sought approval from each of the prospective respondents in order for them to become research respondents by signing an informed consent sheet.

The data was analyzed using both a univariate and multivariate analysis test. The baseline sociodemographic characteristics of age, diabetes duration, the complications of diabetes, and other numerical research variables were described using both mean and standard deviation (SD). The categorical data of gender, education level, income level, marital status and kinship of the diabetes patients were described using frequency and constituent ratios. The correlation tests, namely the Pearson correlation test and the Spearman rank test, were used to determine the relationship between the characteristics of the respondents with diabetes selfmanagement. The multiple linear regression test was used to analyze the factors that influence the family caregiver's diabetes self-management capability. A 2sided $\mathrm{P}<0.05$ was considered to be statistically significant. This study passed the ethical review of the Health Research Ethics Commission of the Faculty of Nursing Universitas Airlangga and it received approval of the research protocol number 1795KEPK.

\section{RESULTS}

The demographic characteristics of the respondents have been presented in Table 1 . The average age of the respondents in this study was 49.49 years old. The majority of the respondents were female (67.2\%), married (91.4\%), and had an education level of junior high school (33.8\%) with a level of income under the regional minimum wage (69.8\%). The average diabetes duration of illness was 48.08 months and they did not have any complications (83.6\%).

The respondent characteristics based on the psychosocial factors have been presented in Table 2 . The majority of respondents $(63.18 \%)$ had a good knowledge of diabetes and they were highly motivated to care for their family members with diabetes (79.09\%). The coping skills of the respondents were, for the majority, in the high category $(61.36 \%)$ as were the aspects of spirituality $(67.27 \%)$. The majority of respondents had family coherence that was in the good category (79.09\%) and they received high family support from the rest of the family $(74.09 \%)$. However, the respondents' perceptions of the role of the nurses in providing services was in the middle category for the majority $(65.55 \%)$ and the majority of the respondents' 
Table 1. Respondents' Sociodemographic Characteristics $(n=220)$

\begin{tabular}{|c|c|c|}
\hline \multirow[t]{2}{*}{ Variable } & \multicolumn{2}{|c|}{ Mean \pm SD or } \\
\hline & & \\
\hline Age (years) & \multicolumn{2}{|c|}{$\frac{\text { (1) }}{49.49 \pm 9.516}$} \\
\hline \multicolumn{3}{|l|}{ Gender } \\
\hline Female & 156 & 67.2 \\
\hline Male & 64 & 27.6 \\
\hline \multicolumn{3}{|l|}{ Level of Education } \\
\hline Elementary School & 56 & 24.1 \\
\hline Junior High School & 78 & 33.6 \\
\hline Senior High School & 70 & 30.2 \\
\hline College & 16 & 6.9 \\
\hline \multicolumn{3}{|l|}{ Income } \\
\hline Under Minimum Wage & 162 & 69.8 \\
\hline Above Minimum Wage & 58 & 25.0 \\
\hline \multicolumn{3}{|l|}{ Marital Status } \\
\hline Unmarried & 2 & 0.9 \\
\hline Married & 212 & 91.4 \\
\hline Widow/Widower & 6 & 2.6 \\
\hline \multicolumn{3}{|l|}{ Kinship } \\
\hline Children & 36 & 15.5 \\
\hline Husband & 53 & 22.8 \\
\hline Wife & 131 & 56.5 \\
\hline \multicolumn{3}{|l|}{ Diabetes Complications } \\
\hline No & 194 & 83.6 \\
\hline Present & 26 & 11.2 \\
\hline Diabetes Duration (month) & $48.0818 \pm 23.6336$ & \\
\hline
\end{tabular}

Table 2. Respondent Characteristics Based on the Psychosocial Factors $(n=220)$

\begin{tabular}{|c|c|c|c|c|c|c|}
\hline \multirow[t]{2}{*}{ Variable } & \multirow[b]{2}{*}{$\mathbf{n}$} & \multirow[b]{2}{*}{$\%$} & \multirow{2}{*}{$\begin{array}{c}\text { Mean } \pm \text { SD (Min- } \\
\text { Max) }\end{array}$} & \multicolumn{2}{|c|}{ Mean difference } & \multirow[t]{2}{*}{ p value } \\
\hline & & & & Female & Male & \\
\hline Diabetes Knowledge & & & $11.6364 \pm 2.80322$ & 11.0769 & $13.0000 \pm$ & 0.000 \\
\hline Poor & 81 & 36.82 & $(5.00-17.00)$ & \pm 2.77207 & 2.39709 & \\
\hline Good & 139 & 63.18 & & & & \\
\hline Motivation & & & $9.3636 \pm 1.87377$ & $9.0833 \pm$ & $10.0469 \pm$ & 0.000 \\
\hline Low & 0 & 0 & $(5.00-12.00)$ & 1.95088 & 1.47390 & \\
\hline Middle & 46 & 20.91 & & & & \\
\hline High & 174 & 79.09 & & & & \\
\hline Coping Skills & & & $39 . .318 \pm$ & $38.1731 \pm$ & $42.1562 \pm$ & 0.000 \\
\hline Low & 13 & 5.91 & 7.02207(22.00- & 7.21125 & 5.66027 & \\
\hline Middle & 72 & 32.3 & $50.00)$ & & & \\
\hline High & 135 & 61.36 & & & & \\
\hline Spirituality & & & $47.1500 \pm 7.23893$ & $46.0769 \pm$ & $49.7656 \pm$ & 0.000 \\
\hline Low & 0 & & (28.00-59.00) & 7.46825 & 5.92745 & \\
\hline Middle & 72 & 32.73 & & & & \\
\hline High & 148 & 67.27 & & & & \\
\hline Family Coherence & & & $72.8500 \pm 8.23348$ & $71.8654 \pm$ & $75.2500 \pm$ & 0.002 \\
\hline Poor & 0 & 0 & $(46.00-88.00)$ & 8.66367 & 6.53683 & \\
\hline Fair & 46 & 20.91 & & & & \\
\hline Good & 174 & 79.09 & & & & \\
\hline Family Support & & & $95.0818 \pm 13.87526$ & $93.0385 \pm$ & $1.0006 \mathrm{E} 2 \pm$ & 0.000 \\
\hline Low & 0 & 0 & $(56.00-116.00)$ & 14.73766 & 9.96641 & \\
\hline Medium & 57 & 25.91 & & & & \\
\hline High & 163 & 74.09 & & & & \\
\hline Role of Nurses & & & $69.4682 \pm 8.91840$ & $68.4295 \pm$ & $72.0000 \pm$ & 0.007 \\
\hline Poor & 0 & 0 & $(50.00-88.00)$ & 9.01906 & 8.19601 & \\
\hline Fair & 142 & 65.55 & & & & \\
\hline Good & 78 & 35.45 & & & & \\
\hline Diabetes Self-management & & & $71.0818 \pm 10.55460$ & $69.3782 \pm$ & $75.2344 \pm$ & 0.000 \\
\hline Poor & 11 & 5 & $(43.00-90.00)$ & 10.98817 & 8.09221 & \\
\hline Fair & 106 & 48.18 & & & & \\
\hline Good & 103 & 46.82 & & & & \\
\hline
\end{tabular}

abilities in terms of managing diabetes was in the middle category $(48.18 \%)$. Table 2 also shows that there are significant differences based on gender, where the average male respondent had diabetes 
Table 3. Relationship Between the Sociodemographic and Psychosocial Factors on Diabetes Self Management Capability $(\mathrm{n}=220)$

\begin{tabular}{lcc}
\hline \multicolumn{1}{c}{ Variable } & Diabetes Self-Management Capability \\
\hline Sociodemographic Factors & $\mathbf{r}$ & p value \\
Age & $-0.212^{* *}$ & 0.000 \\
Gender & $0.262^{* *}$ & 0.000 \\
Education Level & $0.453^{* *}$ & 0.000 \\
Income & $0.207^{* *}$ & 0.002 \\
Marital Status & 0.057 & 0.397 \\
Kinship & $-0.311^{* *}$ & 0.000 \\
Diabetes Complications & -0.024 & 0.724 \\
Diabetes Duration & 0.022 & 0.745 \\
Psychosocial Factors & & \\
Diabetes Knowledge & $0.774^{* *}$ & 0.000 \\
Motivation & $0.808^{* *}$ & 0.000 \\
Coping Skills & $0.808^{* *}$ & 0.000 \\
Spirituality & $0.759^{* *}$ & 0.000 \\
Family Coherence & $0.648^{* *}$ & 0.000 \\
Family Support & $0.817^{* *}$ & 0.000 \\
Role of Nurses & $0.865^{* *}$ & 0.000 \\
\hline **. Correlation is significant at the 0.01 level (2-tailed). &
\end{tabular}

Table 4. Effect of the Psychosocial Factors on Diabetes Self Management Capability

\begin{tabular}{|c|c|c|c|c|c|c|c|}
\hline \multirow{3}{*}{ Variable } & \multicolumn{5}{|c|}{ Coefficient } & \multirow{2}{*}{\multicolumn{2}{|c|}{$\frac{\text { Model reliability test }}{\text { F test }}$}} \\
\hline & \multicolumn{2}{|c|}{$\begin{array}{l}\text { Non-standardized } \\
\text { Coefficients }\end{array}$} & $\begin{array}{l}\text { Standardized } \\
\text { Coefficients }\end{array}$ & \multirow[b]{2}{*}{$\mathbf{t}$} & \multirow[b]{2}{*}{$\mathbf{p}$} & & \\
\hline & B & SE & $\beta$ & & & $\mathbf{F}$ & p \\
\hline Constant & -0.912 & 3.774 & & -.242 & .809 & 184.360 & 0.000 \\
\hline Diabetes Knowledge & 0.176 & 0.203 & 0.047 & 0.868 & 0.386 & & \\
\hline Motivation & 0.529 & 0.682 & 0.094 & 0.775 & 0.439 & & \\
\hline Coping Skills & 0.283 & 0.092 & 0.188 & 3.059 & 0.003 & & \\
\hline Spirituality & -0.120 & 0.119 & -0.082 & -1.003 & 0.317 & & \\
\hline Family Coherence & -0.055 & 0.056 & -0.043 & -0.972 & 0.332 & & \\
\hline Family Support & 0.225 & 0.079 & 0.296 & 2.846 & 0.005 & & \\
\hline Role of Nurses & 0.606 & 0.045 & 0.512 & 13.336 & 0.000 & & \\
\hline Model & $\mathrm{R}$ & & R Square & Adjuste & uare & SE of $t$ & late \\
\hline I & $0.927^{a}$ & & 0.859 & & & & \\
\hline
\end{tabular}

a. Predictors: (Constant), Role of Nurses, Family Coherence, Diabetes Knowledge, Spirituality, Coping Skills, Family Support, Motivation

knowledge, motivation, coping skills, spirituality, family coherence and family support that was better than that of the female respondents.

Table 3 shows that there are three factors, namely marital status, diabetes complications and diabetes duration, that are not related to their diabetes self-management capability. All of the psychosocial factors were associated with diabetes self-management capability.

According to Table 4, it can be seen that only the coping variables, family support, and the perception of the role of the nurses partially influenced the ability of the family caregivers in terms of the diabetes selfmanagement capability ( $p$-value $<0.05$ ). The $F$ test of the model had an $\mathrm{F}$ value $=184,360, \mathrm{p}=0,000<\alpha=$ 0.05 . This explains that the variables of knowledge, motivation, coping, spirituality, family support, and the family caregiver perceptions of the nurses jointly influenced the family caregiver's diabetes selfmanagement capability. It can be concluded that the estimated linear regression model is feasible to use to explain the impact of the variables on the independent management of Type 2 diabetes mellitus by the family caregivers.

\section{DISCUSSION}

The results show that the majority of family caregivers have an ability of diabetes selfmanagement that is in the middle category (48.18\%). However, there are a small proportion of family caregivers who have diabetes self-management capabilities in the poor category (5\%). This is important and it should be a concern of the health care providers. This is because the inability of the families to carry out diabetes self-management can have an impact on the behavior of diabetics, their health status and the emergence of disease complications that can trigger a decrease in quality of life and an early death (International Diabetes Federation [IDF], 2017).

The family-focused approach is likely to maximize the effectiveness of the intervention. Interventions that involve families can provide a new structure for 
the family by adjusting their roles and expectations as needed to ensure optimal patient self-care (Matrook et al., 2018; Pierce \& Lutz, 2012). The empowerment of the family caregivers as an effort to improve the ability of the independent management of diabetes needs to be developed as a preventive promotion effort when managing diabetes (Hu et al., 2014; International Diabetes Federation [IDF], 2017; Matrook et al., 2018).

\section{The Influence of Sociodemographic Factors on Diabetes Self-management Capability}

\section{Age}

The age of the family caregivers can affect diabetes self-management capability. The results of the study, as listed in Table 1, show that the average age of the family caregivers was 49.9 years old. The role of a person as a family caregiver in the long-term care of a disease shows different levels and types of responsibility according to the age of the family caregiver (Pierce \& Lutz, 2012). Age is related to the experience and skills possessed in terms of self-care. In general, an increase in age will increase the experience and skills possessed. This is one of the strong contributors to the development of skills in self-care. However, the results of the study, as shown in Table 3, also show that age has a negative relationship with diabetes self-management capability where the older a person is, the more that it will reduce their diabetes self-management capability. This is likely related to their functional and cognitive capacity where at an older age, there is a decrease in the cognitive function. This can affect their ability to perform self-care (Riegel, Jaarsma, \& Strömberg, 2012).

\section{Gender}

The results of the study, as listed in Table 1, show that the majority of family caregivers were women $(67.2 \%)$. This is consistent with the previous study which states that women are more likely to carry out their role as a family caregiver (Pierce \& Lutz, 2012). The results of the study, as shown in Table 2, show that gender differences influence diabetes selfmanagement capability. The average family caregiver needs to have knowledge, motivation, coping skills, spirituality, the perception of family coherence, and family support as well as the perception of the role of the nurses. In this respect, the male caregivers have higher values than the female family caregivers. There needs to be attention paid by the health care providers in terms of their health promotion efforts because, as is well known, the majority of family caregivers are women.

\section{Marital status}

The results of the study, as listed in Table 1, show that the majority of the family caregivers are married with a life partner (91.4\%). The results showed that marital status did not correlate with diabetes selfmanagement skills (Table 3). This is likely due to the fact that some of the family caregivers do not have a life partner but they still get adequate support from their other family members. This is shown in Table 2 where the majority of the respondents (74.09\%) get support from their families in the high category, meaning that they can still develop their diabetes self management skills. However, it must still be a concern that someone who has a spouse will find it easier to get help from their family in the form of information, assessments, instruments and emotional support (Hensarling, 2009). A healthy spouse will automatically assume themselves to be the caregivers of their partner (Pierce \& Lutz, 2012).

\section{Socioeconomic status}

The results of the study in Table 1 show that the majority of respondents had a junior high school education level (33.8\%), with an income level below the regional minimum wage (69.8\%). Health promotion efforts in the prevention of diabetes complications need to be developed on a massive scale because the inability to manage diabetes independently will have an impact on disease complications. This can cause increased health care costs (World Health Organization [WHO], 2016). Variations in socioeconomic status affect the role of the family caregiver, especially in reference to longterm care. Families from the higher socioeconomic groups show better care than those from the low socioeconomic groups (Pierce \& Lutz, 2012).

\section{Kinship}

The results in Table 1 show that the majority of family caregivers who treat people with diabetes are their life partners (79.30\%), especially wives (56.5\%). This is consistent with the previous opinion that for patients who are adults, a spouse or adult child is their primary caregiver (Pierce \& Lutz, 2012). Adult children have a filial obligation to take care of their parents (Jones, Winslow, Lee, Burns, \& Zhang, 2011). However, kinship as a life partner shows a stronger relationship in care compared to other kinship relationships (Friedman, Bowden, and Jones, 2010). Kinship as a life partner involves a stronger emotional relationship than an adult children-parent relationship. Adult children who care for their parents have a double obligation, namely the filial obligation to care for their parents and the responsibilities related to taking care of their own families (wife/ husband and children).The results in Table 3 show that there is a significant relationship between kinship and diabetes self-management capability. The kinship relationship determines the caregiving process. The kinship relationship will determine the family caregiver's motivation when caring for people with Type 2 diabetes mellitus (Pierce \& Lutz, 2012).

\section{The Influence of Psychosocial Factors on Diabetes Self-management Capability}

The results of the study show that psychosocial factors influence the ability of the family caregivers in relation to diabetes self-management. The correlation test results in Table 3 show that diabetes knowledge, motivation, coping skills, spirituality, family 
coherence, family support, and the perception of the role of the nurses have a significant effect on diabetes self-management capability. Based on the results of modeling through multiple linear regression as listed in Table 4, it can be seen that the psychosocial variables of knowledge, motivation, coping skills, spiritual aspects, family support, and the family caregiver perception of the nurses jointly affects diabetes self-management capability. Based on Table 4 , it also can be seen that the R-value of 0.927 shows that there are multiple correlations (knowledge, motivation, coping, spirituality, family support, and family caregiver perceptions of nurses) with the ability to independently manage diabetes by the family caregiver.

The adjusted R Square value of 0.854 shows that the magnitude of the role or the contribution of the variables of knowledge, motivation, coping, spirituality, family support, and the family caregiver perceptions of the nurses is able to explain the variable ability of independent management in reference to Type 2 diabetics by $85.4 \%$. The results of this study are consistent with the previous research which states that the factors of social status, psychological conditions, and social support can affect the ability of self-care and in turn, quality of life (Walker et al., 2014).

\section{Diabetes Knowledge}

The results in Table 3 show that knowledge of diabetes has a significant positive relationship with diabetes self-management capability $(r=0.77 ; \mathrm{p}=$ 0.000 ). Providing the right education needs to be done in order to improve the ability of the family caregivers in terms of their diabetes self-management capability. The results of the study in Table 2 further show that there are still family caregivers who have poor diabetes knowledge (36.8\%). Some of the families show helplessness when helping the sufferers to manage and master adaptive tasks related to their health problems. This is due to the lack of information held by the family and a lack of understanding and even incorrect information given to the family about the health problems that they face. Ignorance related to the treatment process will cause excessive stress for the family caregivers, thereby reducing their motivation, influencing coping and affecting their ability to treat diabetes (Sakanashi \& Fujita, 2017).

\section{Motivation}

The results show that the majority of family caregivers (79.09\%) have high motivation when treating their diabetic family members. The motivation owned by someone will encourage them to achieve their goals. The results of the study in Table 3 show that motivation has a significant positive relationship with diabetes self-management capability $(r=0.808 ; p=0.000)$. The higher the motivation, the more that their diabetes selfmanagement capability will increase in quality. This is due to the abilities of the family caregiver being influenced by their motivation when caring for their sick family member. The high motivation that comes from the expectations related to the results of the care process will increase their commitment to caring for their ill family members (Friedman, Bowden \& Jones, 2010).

\section{Coping Skills}

The results in Table 2 show that the majority of the family caregivers have high coping skills (61.36\%). The results of the study, as listed in Table 3, show that coping skills have a positive and significant relationship with diabetes self-management capability $(r=0.808 ; p=0.000)$ where the better the coping skills, the better the independent management of diabetes by the family caregiver. Ineffective coping is marked by destructive behavior that can appear in the family caregiver. There is also the inability of the caregivers to manage the stressors that arise due to the limitations in their social activities and free time, violations of privacy, the disruption of the household and work routines, the demand for dual roles, a lack of social support and assistance from other family members, disruptions in their family relationships and the lack of aid from humanitarian service agencies and health professionals (Friedman, Bowden \& Jones, 2010).

\section{Spirituality}

The results in Table 2 show that the majority of family caregivers have a high spiritual aspect (67.27\%). Table 3 shows that the spirituality aspect has a positive and significant relationship with diabetes self-management capability $(r=0.759 ; p=0.000)$, where the higher the spirituality aspect, the better the independent management of diabetes by the family caregiver. The results of this study correspond to those of the previous studies which state that the spirituality aspects of the caregiver affects the general health and well-being of the caregiver overall (Rabinowitz et al., 2009). Spirituality affects the coping mechanisms used by encouraging the caregiver to be more constructive (Chang, Noonan, \& Tennstedt, 1998). It also increases the commitment of the family caregivers when caring for their family members (Sakanashi \& Fujita, 2017).

\section{Family Coherence}

The results of the study in Table 2 show that the majority of the family caregivers have a good perception of family coherence $(79.09 \%)$. There is a positive and significant relationship between family coherence and diabetes self-management capability $(r=0.648 ; p=0.000)$, where the better the perception of family coherence, the better the independent management of diabetes by the family caregivers (Table 3). The results of this study are consistent with those of the previous studies which state that family coherence can help to support the positive assessment of family caregivers related to the demands of care, thus facilitating effective coping and the management of care (Jones et al., 2011). Family coherence is related to the ability of the family 
members to adapt when dealing with stressful life events (Antonovsky \& Sourani, 1988).

\section{Family Support}

The results of the study, as listed in Tables 2 and 3, show that the majority of family caregivers have family support that is in the good category (74.09\%). There is a positive and significant relationship between family coherence and diabetes selfmanagement capability $(r=0.817 ; p=0.000)$ where the higher the family support received, the better the independent management of diabetes by the family caregiver. The results of this study are consistent with the previous study, which states that family support will increase the empowerment of the family caregivers (Sakanashi \& Fujita, 2017). Social support from other family members will reduce the negative impact and improve the positive aspects of caregiving (Jones, Winslow, et al., 2011). A lack of social support and assistance from other family members will reduce the resources of the family caregiver in turn (Friedman, Bowden, \& Jones, 2010).

\section{Role of Nurses}

The results of the study, as listed in Table 3, show that the majority of family caregivers have a strong perception related to the role of the nurses $(65.55 \%)$. This is not something extraordinary. It should be a common concern to ensure that the family caregiver's perception of the role that has been performed by the nurses in helping to treat people with diabetes is in the quite good category. More serious efforts are needed to increase the role of the practitioners in managing diabetes. There is a positive and significant relationship between family coherence and diabetes self-management capability $(r=0.648 ; p=0.000)$ as listed in Table 3 . The better the perception of the role of the nurses, the better the independent management of diabetes by the family caregiver. Support from health professionals has been proven to prevent the depression symptoms that appear in the family caregivers. The social support of the caregivers has a positive effect in the form of feelings of satisfaction, love, and pride (Imanigoghary et al., 2017). The majority of respondents in this study believe that caregiving makes them stronger, more patient, more appreciative of the time spent with their family and less judgmental of others. The results showed that the role of the nurses in providing support to the caregivers was through providing advocacy education. Advocacy is needed to improve the service support of the family caregivers through family education and through the preparation of the skills required by the caregivers (Grant \& Ferrell, 2012).

\section{CONCLUSION}

The results showed that the demographic and psychosocial factors together influence diabetes selfmanagement capability. Sociodemographic factors such as age, gender, socioeconomic status, and kinship relations have a positive relationship with the ability of the family caregivers in the independent management of Type 2 diabetes mellitus. There are also psychosocial factors such as knowledge, motivation, coping skills, spirituality, family support, and the perceptions of the family caregivers of the nurses. These together affect diabetes selfmanagement capability. This study indicates that health care providers, in the promotion and prevention of Type 2 diabetes mellitus, should understand the interaction between the demographic factors, knowledge, the environment, and other diabetes-related factors. Paying attention to the sociodemographic and psychosocial factors can provide insights to improve glycemic control and health status, to prevent complications and premature death, and also to improve the quality of life of people with Type 2 diabetes mellitus. Further research is needed with a qualitative research design in order to explore the family caregivers when they are carrying out the independent management of diabetes. Further research in the form of experimental research by way of empowerment interventions evaluating the psychosocial factors should be done to prove the effectiveness of the involved factors concerning the ability of independent management of Type 2 diabetes mellitus.

\section{REFERENCES}

Antonovsky, A., \& Sourani, T. (1988). Family Sense of Coherence and Family Adaptation. Journal of Marriage and the Family, 50(1), 79-92. https://doi.org/10.2307/352429

Badriah, S., Wiarsih, W., \& Permatasari, H. (2017). Pengalaman Keluarga dalam Merawat Lanjut Usia dengan Diabetes Mellitus. Jurnal Keperawatan Indonesia, 17(2), 57-64. https://doi.org/10.7454/jki.v17i2.401

Chang, B.-H., Noonan, A. E., \& Tennstedt, S. L. (1998). The role of religion/spirituality in coping with caregiving for disabled elders. Gerontologist, 38(4), 463-470.

Daaleman, T. P., \& Frey, B. B. (2004). The Spirituality Index of Well-Being: A New Instrument for Health-Related Quality of Life Research. Annals of Family Medicine, 2(5), 499-503. https://doi.org/10.1370/afm.89.Department

Friedman, M.M., Bowden, V.R., Jones, E.G (2010) Family Nursing; Research, Theory, and Practice.Terjemahan oleh Achir Yani S. Hamid, dkk 2010.. Buku Ajar Keperawatan Keluarga; Riset, Teori dan Praktik. Edisi 5.Jakarta: EGC

Grant, M., \& Ferrell, B. (2012). Nursing Role Implications for Family Caregiving. Seminars in Oncology Nursing. https://doi.org/10.1016/j.soncn.2012.09.011

Hamby, S., Grych, J. H., \& Banyard, V. (2015). Coping Scale. TN: Life Paths Research Program. https://doi.org/10.13140/RG.2.1.3094.0001

Hensarling, J. (2009). Development and Psychometric Testing of Hensarling's Diabetes Family Support 
Scale. Texas Woman's University.

Holmefur, M., Sundberg, K., Wettergren, L., \& Langiuseklo, A. (2014). Measurement properties of the 13-item sense of coherence scale using Rasch analysis Measurement properties of the 13-item sense of coherence scale using Rasch analysis. Quality of Life Research, (November). https://doi.org/10.1007/s11136-014-0866-6

Hu, J., Wallace, D., McCoy, T., \& Amirehsani, K. (2014). NIH Public Access. Diabetes Educator, 40(1), 4859. https://doi.org/10.1177/0145721713512682

Imanigoghary, Z., Peyrovi, H., Nouhi, E., Kazemi, M., Nouhi, E., \& Kazemi, M. (2017). The Role of Nurses in Coping Process of Family Caregivers of Vegetative Patients: A Qualitative Study. International Journal of Community Based Nursing and Midwifery, 5(1), 70-81. Retrieved from

http://www.ncbi.nlm.nih.gov/pubmed/28097 180\%0Ahttp://www.pubmedcentral.nih.gov/a rticlerender.fcgi?artid=PMC5219567

International Diabetes Federation [IDF]. (2017). IDF Diabetes Atlas Eighth edition 2017. International Diabetes Federation. IDF Diabetes Atlas, 8th edn. Brussels, Belgium: International Diabetes Federation, 2017. http://www.diabetesatlas.org. https://doi.org/http://dx.doi. org/10.1016/S0140-6736(16)31679-8.

Jones, P. S., Winslow, B. W., Lee, J. W., Burns, M., \& Zhang, X. E. (2011). Development of a Caregiver Empowerment Model to Promote Positive Outcomes. Journal of Family Nursing, 17(1), 1128. https://doi.org/10.1177/1074840710394854

Kolmer, D. B. genaamd, Tellings, A., Gelissen, J., Garretsen, H., \& Bongers, I. (2008). Ranked motives of long-term care providing family caregivers. Scandinavian Journal of Caring Sciences, 22, 29-39.

Matrook, K. A., Cowman, S., Dovey, S. M., Smith, S. M., McGilloway, S., \& Whitford, D. L. (2018). Familybased interventions for adults with type 2 diabetes mellitus. Cochrane Database of Systematic Reviews, (7), 1-19. https://doi.org/10.1002/14651858.cd013064

Pierce, L. L., \& Lutz, B. J. (2012). Family Caregiving. In I. M. Lubkin \& P. D. Larsen (Eds.), Chronic Illnes: Impact and Intervention (8th Ed, pp. 245-288). Burlington, MA: Jones \& Bartlett Learning, LLC, an Ascend Learning Company. https://doi.org/10.1177/1742395312443692

Powers, M. A., Bardsley, J., Cypress, M., Duker, P., Funnell, M. M., Fischl, A. H., ... Vivian, E. (2015). Diabetes self-management education and support in type 2 diabetes: A joint position statement of the American Diabetes Association, the American Association of diabetes educators, and the Academy of nutrition and dietetics. Clinical Diabetes, 34(2), 70-80.

https://doi.org/10.2337/diaclin.34.2.70
Putri, H., Yeni, F., \& Handayani, T. (2013). Hubungan Peran Keluarga Dengan Pengendalian Kadar Gula Darah Pada Pasien Diabetes Melitus di Wilayah Kerja Puskesmas Pauh Padang. NERS Jurnal Keperawatan, 9(2), 133-140. https://doi.org/10.25077/njk.9.2.136142.2013

Rabinowitz, Y. G., Mausbach, B. T., Atkinson, P. J., \& Gallagher-Thompson, D. (2009). NIH Public Access. Aging Ment Health, 13(6), 788-798. https://doi.org/10.1080/1360786090304644 6

Riegel, B., Jaarsma, T., \& Strömberg, A. (2012). A Middle-Range Theory of Self-Care of Chronic Illness. Advances in Nursing Science, 3(35), 194204.

https://doi.org/http://dx.doi.org/10.1097/AN S.0b013e318261b1ba

Rothman, R. L., Malone, R., Bryant, B., Wolfe, C., Padgett, P., Dewalt, D. A., ... Pignone, M. (2005). The Spoken Knowledge in Low Literacy in Diabetes Scale: A Diabetes Knowledge Scale for Vulnerable Patients. Diabetes Educator, 31(2), 215-224.

https://doi.org/10.1177/0145721705275002

Sakanashi, S., \& Fujita, K. (2017). Empowerment of family caregivers of adults and elderly persons : A concept analysis. International Journal of NUrsing Practice, e12573(May), 1-9. https://doi.org/10.1111/ijn.12573

Van der bijl, J., van Poelgeest-Eeltink, A., ShortridgeBaggett, L. (2001). The psychometric properties of the diabetes management self-efficacy scale for patients with type 2 diabetes mellitus. Journal of Advanced Nursing; 30 (2). https://doi.org/10.1046/j.13652648.1999.01077.x

Walker, R. J., Gebregziabher, M., Martin-Harris, B., \& Edege, L. E. (2014). Independent Effects of Socioeconomic and Psychological Social Determinants of Health on Self-Care and Outcomes in Type 2 Diabetes. Gen Hosp Psychiatry, 36(6), 662-668. https://doi.org/10.1016/j.genhosppsych.2014. 06.011.Independent

World Health Organization [WHO]. (2016). Global report on diabetes.World Health Organization (Vol. 58). Geneva. https://doi.org/10.1128/AAC.03728-14

World Health Organization [WHO]. (2018). Noncommunicable Diseases Country Profiles 2018. World Health Organization. Geneva: World Health Organization. https://doi.org/10.1056/NEJMra1109345

$\mathrm{Wu}, \mathrm{S} . \mathrm{F}$. (2007). Effectiveness of self-management for persons with type 2 diabetes following the implementation of a self- efficacy enhancing intervention program in Taiwan. Queensland University of Technology. Retrieved from http://eprints.qut.edu.au/ 